\title{
Prognostic significance of early aortic remodeling in acute uncomplicated type $B$ aortic dissection and intramural hematoma
}

Anna M. Sailer, MD, PhD, ${ }^{\mathrm{a}, \mathrm{f}}$ Patricia J. Nelemans, MD, PhD, ${ }^{\mathrm{g}}$ Trevor J. Hastie, PhD, ${ }^{\mathrm{c}, \mathrm{e}}$ Anne S. Chin, MD, ${ }^{\mathrm{a}}$ Mark Huininga, MD, ${ }^{\mathrm{h}}$ Peter Chiu, MD, ${ }^{\mathrm{b}}$ Michael P. Fischbein, MD, PhD,${ }^{\mathrm{b}}$ Michael D. Dake, MD,, $\mathrm{d}$ D. Craig Miller, MD, ${ }^{\mathrm{b}}$ G. W. Schurink, MD, PhD, ${ }^{\mathrm{h}}$ and Dominik Fleischmann, MD ${ }^{\mathrm{a}, \mathrm{d}}$

\section{ABSTRACT}

Background: Patients with Stanford type B aortic dissections (ADs) are at risk of long-term disease progression and late complications. The aim of this study was to evaluate the natural course and evolution of acute type $\mathrm{B}$ AD and intramural hematomas (IMHs) in patients who presented without complications during their initial hospital admission and who were treated with optimal medical management (MM).

Methods: Databases from 2 aortic centers in Europe and the United States were used to identify 136 patients with acute type B AD $(n=92)$ and acute type B IMH $(\mathrm{n}=44)$ who presented without complications during their index admission and were treated with MM. Computed tomography angiography scans were available at onset ( $\leq 14$ days) and during follow-up for those patients. Relevant data, including evidence of adverse events during follow-up (AE; defined according to current guidelines), were retrieved from medical records and by reviewing computed tomography scan images. Aortic diameters were measured with dedicated 3-dimensional software.

Results: The 1-, 2-, and 5-year event-free survival rates of patients with type B AD were $84.3 \%$ (95\% confidence interval [CI], 74.4-90.6), 75.4\% (95\% CI, 64.0-83.7), and 62.6\% (95\% CI, 68.9-73.6), respectively. Corresponding estimates for IMH were 76.5\% (95\% CI, 57.8-87.8), 76.5\% (95\% CI, 57.8-87.8), and $68.9 \%(95 \% \mathrm{CI}, 45.2-83.9)$, respectively. In patients with type $\mathrm{B} \mathrm{AD}$, risk of an $\mathrm{AE}$ increased with aortic growth within the first 6 months after onset. A diameter increase of $5 \mathrm{~mm}$ in the first half year was associated with a relative risk for AE of 2.29 (95\% CI, 1.70-3.09) compared with the median 6 months' growth of $2.4 \mathrm{~mm}$. In approximately $60 \%$ of patients with IMH, the abnormality resolved within 12 months and in the patients with nonresolving IMH, risk of an adverse event was greatest in the first year after onset and remained stable thereafter.

Conclusions: More than one third of patients with initially uncomplicated type B $\mathrm{AD}$ suffer an $\mathrm{AE}$ under MM within 5 years of initial diagnosis. In patients with

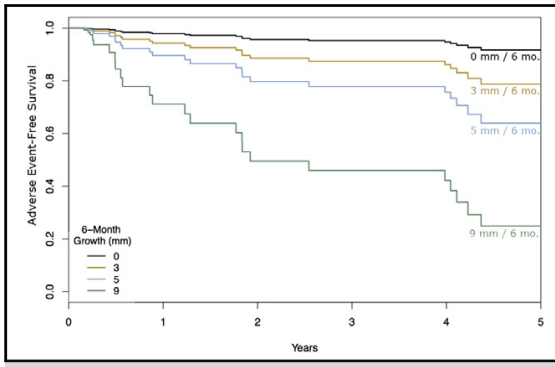

Adverse event-free survival in uncomplicated type $B$ dissection by 6 -month growth rates.

\section{Central Message}

Most adverse events in patients with nonresolving intramural hematoma occur in the first year. Aortic growth in the first 6 months is associated with late adverse events in patients with uncomplicated type B aortic dissection.

\section{Perspective}

Nonresolving intramural hematoma should be followed closely in the first year, because this is the time when most adverse events occur. Resolving intramural hematoma typically remain stable. In patients with initially uncomplicated type B aortic dissection, a faster growth within the first 6 months under medical management is associated with a greater risk of adverse events.

See Editorial Commentary page 1201.

See Editorial page 1171. nonresolving IMH, most adverse events are observed in the first year after onset. In patients with type $\mathrm{B} A \mathrm{D}$ an early aortic growth is associated with a greater risk of AE. (J Thorac Cardiovasc Surg 2017;154:1192-200)

\footnotetext{
From the Departments of ${ }^{\mathrm{a}}$ Radiology, ${ }^{\mathrm{b}}$ Cardiothoracic Surgery, and ${ }^{\mathrm{c}}$ Biomedical Data Sciences and ${ }^{\mathrm{d}}$ Stanford Cardiovascular Institute, Stanford University School of Medicine; ${ }^{\text {e}}$ Department of Statistics, Stanford University, Stanford, Calif; and the Departments of ${ }^{\mathrm{f}}$ Radiology, ${ }^{\mathrm{g}}$ Epidemiology, and ${ }^{\mathrm{h}}$ Vascular Surgery, Maastricht University Medical Center, Maastricht, The Netherlands.

A. M. Sailer is supported by the Dutch Royal Society for Arts and Sciences (KNAW), and P. Chiu is supported by a KL2 Mentored Career Development Award of the Stanford Clinical and Translational Science Award to Spectrum (NIH KL2 TR 001083). The project was supported by a National Institutes of Health Clinical and Translational Science Award number UL1 RR025744.
}

Received for publication Oct 20, 2016; revisions received March 2, 2017; accepted for publication April 3, 2017; available ahead of print June 28, 2017.

Address for reprints: Dominik Fleischmann, MD, Department of Radiology, Stanford University School of Medicine, 300 Pasteur Drive, S-072, Stanford, CA 943055105 (E-mail: d.fleischmann@stanford.edu). $0022-5223 / \$ 36.00$

Copyright (C) 2017 by The American Association for Thoracic Surgery http://dx.doi.org/10.1016/j.jtcvs.2017.04.064 


\section{Abbreviations and Acronyms}
$\mathrm{AD}=$ aortic dissection
IMH = intramural hematoma
$\mathrm{MM}=$ medical management
$\mathrm{CT}=$ computed tomography
TEVAR $=$ thoracic endovascular aortic repair
$\mathrm{RR} \quad=$ relative risk

Scanning this QR code will take

you to a supplemental video for the article.

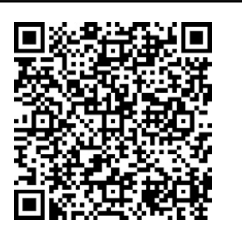

Type B aortic dissections (ADs) and intramural hematomas (IMHs) share the same underlying aortic wall pathology, present with the same clinical symptoms, and develop similar complications. ${ }^{1}$ Although classic AD is characterized by the presence of an intimal tear and formation of a false channel within the medial layer of the aortic wall, no perfused false lumen is visible in IMH. Acute type B $\mathrm{AD}$ is a well-recognized clinical challenge with a broad range of immediate clinical outcomes. ${ }^{2,3}$ Some patients present with potentially life-threatening complications, such as rupture and organ malperfusion, and some with refractory hypertension or uncontrollable pain despite medication. In these patients, urgent endovascular or open surgical repair is indicated. Patients presenting without a life-threatening event are considered uncomplicated. Traditionally, these patients are treated conservatively, with medical management $(\mathrm{MM}){ }^{4,5}$ The potential role of endovascular repair for patients with uncomplicated type $\mathrm{B} A D$ is a much-debated topic. Patients who are medically managed require lifelong surveillance to monitor disease progression and prevent late adverse events. ${ }^{6,7}$ Disadvantages of this strategy include the risk of poor patient compliance and incomplete follow-up. With progression of the aortic wall degeneration, aortic enlargement, and increasing stiffness of the intimal flap, treatment might become more complex and extensive at a later stage of the disease. ${ }^{8,9}$ Finally, when a patient with chronic type B AD presents acutely, the risk of an unfavorable outcome after treatment is greater than after an elective intervention.

Early thoracic endovascular aortic repair (TEVAR) has been proposed as an alternative strategy to prevent late adverse events. ${ }^{10-14}$ Although perioperative mortality is less than $5 \%$, TEVAR for type B AD can be associated with significant complications, including paraplegia, stroke, and retrograde type A dissection. ${ }^{15-17}$ In this context, a thorough understanding of the course of disease in dissections may be helpful. More insights into the evolution and aortic diameter growth in dissection and IMH and the associated risk of complications relating to the particular type of anatomic aortic involvement are required. Here we were particularly interested to explore whether the rate of progression in the first months after onset of the disease might be predictive of later risk of complications (Video 1). The aim of this study was to evaluate the natural history and aortic remodeling in patients with initially uncomplicated acute type B AD or uncomplicated acute type B IMHs.

\section{METHODS}

This study was approved by the institutional review boards of the participating institutions. Informed consent was waived, given the retrospective nature of this work.

\section{Patients}

Databases from 2 large aortic centers in the United States and Europe were used to identify patients presenting with acute type B AD or IMH between January 2002 and December 2012 and who survived their initial hospital admission without complications. Patients for whom data from computed tomography (CT) angiography scans at presentation and during follow-up visits were available were selected for further analysis. All patients initially were treated with MM and followed up according to the standard clinical regimen. Data on patient characteristics and clinical course were retrieved retrospectively from the medical records. Relevant patient data included patient age, sex, presence of connective tissue disease, and presence of hypertension.

\section{Definitions}

Acute uncomplicated Stanford type B AD is defined as a dissection not involving the ascending aorta, presenting within 14 days of symptom onset,

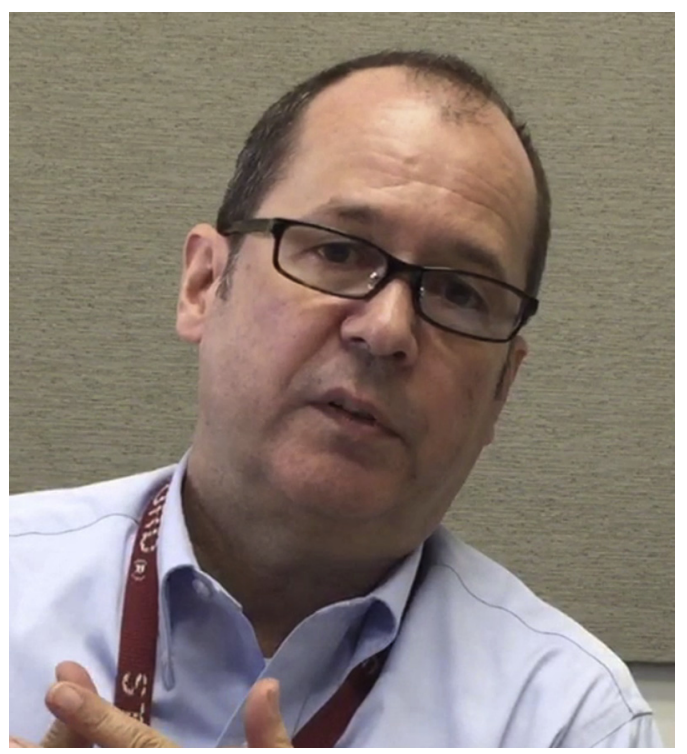

VIDEO 1. In this short ( 2 minutes, 45 seconds) introductory video, the paper's senior author-Dr Dominik Fleischmann-explains the motivation and key findings of this study. Video available at: http://www.jtcvsonline. org/article/S0022-5223(17)30898-X/addons. 
without any of the following complications at presentation or during index hospitalization: death, aortic rupture or signs of impending rupture, organ or limb ischemia, and uncontrollable pain or hypertension.

Acute uncomplicated Stanford type B IMH is defined as an IMH not involving the ascending aorta, presenting within 14 days of symptom onset, without a dissection flap and without radiologic evidence of a penetrating aortic ulcer, ${ }^{18}$ and without any of the above complications at presentation or during the index hospitalization: death, aortic rupture or signs of impending rupture, organ or limb ischemia, and uncontrollable pain or hypertension.

\section{Aortic Remodeling}

$\mathrm{CT}$ images acquired at the time of diagnosis and during all follow-up visits were used to evaluate aortic growth. On each individual scan, aortic diameters were measured at several predefined levels. The parameter used to evaluate aortic growth was the maximum aortic diameter. For each patient, the slope of aortic growth was calculated individually based on baseline maximum aortic diameter measurements and all repeated follow-up diameters. Baseline was considered the scan at discharge from the index hospitalization. Aortic growth rate slopes during the first 6 months were used to correlate with occurrence of adverse events during follow-up. We also recorded whether and when resolution of the dissection or IMH was observed, or whether an IMH evolved into a dissection. Resolution was defined as absence of high-density intramural aortic rim on noncontrastenhanced CT scans and absence of an intimal flap on the contrastenhanced CT angiography.

\section{Outcomes}

The primary outcome measure was the cumulative probability of adverse event-free survival. Patients were classified as having an adverse event if one or more of the following events were diagnosed clinically and/or by CT angiography: fatal or nonfatal signs of aortic rupture, organ or limb ischemia, aortic aneurysm formation (thoracic aortic diameter $\geq 6 \mathrm{~cm}$ ), rapid aortic diameter growth of $\geq 10 \mathrm{~mm}$ within 12 months of follow-up, or new refractory hypertension or pain that could not be controlled with medical therapy. To distinguish between clinically stable patients with asymptomatic progression of aortic diameters requiring elective intervention versus those requiring urgent treatment, we also calculated the cumulative probability of event-free survival from the subset of urgent late adverse events as a secondary outcome measure. Urgent late adverse events include fatal or nonfatal signs of aortic rupture as well as organ or limb ischemia, but exclude clinically stable asymptomatic aneurysms.

\section{Image Analysis}

CT angiography images at presentation and all follow-up CT scans were reviewed for all patients. The standard scan regimen was at onset, discharge, 3 or 6 months, 12 months, and yearly thereafter, but it could differ for individual patients, depending on findings. Images were analyzed with dedicated 3-dimensional software iNtuition (TeraRecon, Inc, Foster City, Calif) to measure the aortic diameters. Measurements were performed with the orthogonal method, after the generation of straightened multiplanar reformations. In all studies, radiologic signs of adverse events, such as organ malperfusion and rupture, as well as imaging evidence of pathology resolution, were reviewed.

\section{Statistical Analysis}

Baseline characteristics for the total study population and the groups with type $\mathrm{B} A \mathrm{AD}$ or type $\mathrm{B}$ IMH are described as absolute numbers and percentages for categorical variables and as mean ( \pm standard deviation) or median with interquartile range for continuous variables. Differences between groups were tested with the $\chi^{2}$ test for proportions and with the $t$ test for independent samples for continuous variables (if normally distributed) or the nonparametric Mann-Whitney $U$ test (if not normally distributed).

Initial 6 months' growth at the maximum aortic diameter of the dissections was calculated for each patient based on the repeated measurements at this landmark. The influence of growth rates in the initial 6 months on primary and secondary outcome was evaluated with a Cox proportional hazards model. In patients with IMH, a distinction was made between patients with and without resorption of the IMH. Cumulative probabilities of eventfree survival from all adverse events at 1 year, 2 years, and 5 years after onset were calculated with Kaplan-Meier survival analysis. Prespecified subgroup analyses were performed for (1) patients with type B AD versus IMH; (2) patients with aortic growth rates of $0,3,5$, and $9 \mathrm{~mm}$ within in the first 6 months; and (3) patients with resorbing versus nonresorbing IMH. Differences in probabilities of event-free survival between subgroups were tested for statistical significance via the log rank test. Cumulative probability of resolution of an IMH within 1, 6, and 12 months also was calculated with time-to-event analysis. Follow-up ended on the date on which an adverse event occurred or the date of the last observation (if no adverse event occurred). A $P$ value $\leq .05$ was considered to indicate statistical significance. The analyses were performed with SPSS, version 21 (IBM Corp, Armonk, NY) or R Core Team (2016, https://www.Rproject.org) and Thernau $\mathrm{T}$ (2015, http://CRAN.R-project.org/ package $=$ survival).

\section{RESULTS}

Figure 1 presents a flow diagram of patient inclusion. Of 207 eligible patients with acute uncomplicated AD, 71 patients had to be excluded because their care was transferred back to the referring center for further follow-up. The final study population consisted of 136 patients, including 92 patients with uncomplicated type $\mathrm{B} A D$ and 44 patients with uncomplicated type B IMH. Three of the type B AD dissections were iatrogenic, following cardiac and other arterial catheterizations; 6 of the dissections affected only the abdominal aorta. Two or more follow-up CT scans were available for $90.2 \%$ of patients with type $\mathrm{B} A D$ and for $90.9 \%$ of patients with IMH. Follow-up was based on 6

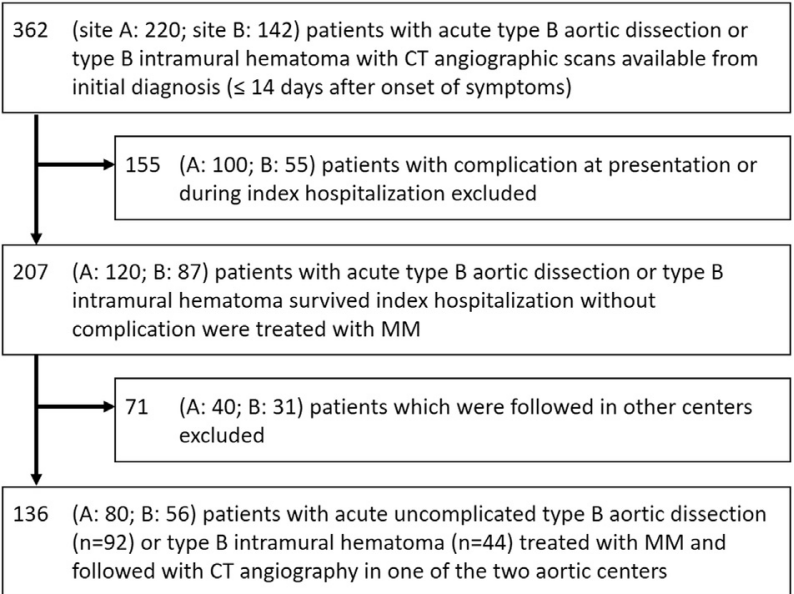

FIGURE 1. Flowchart of patient inclusion. Numbers in parentheses show numbers of patients from each center (site A; site B). $C T$, Computed tomography; $M M$, medical management. 
TABLE 1. Baseline patient characteristics for all patients as well as for the groups classic type B AD and IMH

\begin{tabular}{|c|c|c|c|c|}
\hline & All patients $(n=136)$ & Type B AD $(n=92)$ & IMH $(n=44)$ & $P$ value \\
\hline Male sex, $\mathrm{n}(\%)$ & $86(63.2)$ & $61(66.3)$ & $25(56.8)$ & .343 \\
\hline Age at onset, $\mathrm{y}$, mean $\pm \mathrm{SD}$ & $60 \pm 16$ & $55 \pm 16$ & $69 \pm 12$ & .049 \\
\hline Connective tissue disease, $\mathrm{n}(\%)$ & $19(14)$ & $16(17.4)$ & $3(6.8)$ & .117 \\
\hline Hypertension, n (\%) & $119(87.5)$ & $79(85.9)$ & $40(90.9)$ & .581 \\
\hline Hyperlipidemia, n (\%) & $64(47)$ & $38(41.4)$ & $26(59.1)$ & .038 \\
\hline Diabetes, n (\%) & $9(6.6)$ & $7(7.6)$ & $2(4.5)$ & .390 \\
\hline Smoker (active and former), $\mathrm{n}(\%)$ & 77 (56.6) & $47(51.1)$ & $30(68.2)$ & .157 \\
\hline Iatrogenic dissection/trauma, $\mathrm{n}(\%)$ & $3(2.2)$ & $3(2.2)$ & $0(0)$ & .225 \\
\hline Illicit drug use, n (\%) & $1(0.7)$ & $1(1.1)$ & $0(0)$ & .890 \\
\hline Vasculitis, $\mathrm{n}(\%)$ & $1(0.7)$ & $1(1.1)$ & $0(0)$ & .890 \\
\hline Pregnancy, n (\%) & $0(0)$ & $0(0)$ & $0(0)$ & 1.000 \\
\hline $\begin{array}{l}\text { Inherited conditions (Turner syndrome, polycystic } \\
\text { kidney disease, other), } \mathrm{n}(\%)\end{array}$ & $0(0)$ & $0(0)$ & $0(0)$ & 1.000 \\
\hline
\end{tabular}

$A D$, Aortic dissection; $I M H$, intramural hematoma; $S D$, standard deviation.

or more CT scans in $33.6 \%$ and $22.7 \%$ of type B AD and IMH patients, respectively.

Baseline patient characteristics are shown in Table 1. Patients with type $\mathrm{B} A \mathrm{D}$ were significantly younger at presentation than patients with $\mathrm{IMH}(P=.049)$, and the presence of hyperlipidemia was significantly less common compared with patients with $\operatorname{IMH}(P=.038)$. In the type $\mathrm{B} \mathrm{AD}$ group, 16 patients $(17.4 \%)$ had connective tissue disease, whereas in the IMH group, there were only 3 affected patients $(6.8 \%)$, but this difference was not significant $(P=.166)$.
The types and frequencies of adverse events observed over a median follow-up of 861 days in patients with uncomplicated type $\mathrm{B} \mathrm{AD}$ and $\mathrm{IMH}$ are presented in Table 2.

\section{Aortic Remodeling and Adverse Events in Patients With AD}

A total of 33 of $92(36 \%)$ patients with type B AD developed an adverse event during follow-up, of which 26 of 33 $(78.8 \%)$ were related to aortic critical diameter

TABLE 2. Overview of events during follow-up for all patients and by groups: type B AD and IMH

\begin{tabular}{|c|c|c|c|}
\hline & All $(\mathbf{n}=136)$ & Type B AD $(\mathbf{n}=92)$ & IMH $(n=44)$ \\
\hline \multicolumn{4}{|l|}{ All adverse events } \\
\hline Rupture & $3(2.2)$ & $1(1.1)$ & $2(4.5)$ \\
\hline Renal ischemia & $5(3.7)$ & $4(4.3)$ & $1(2.3)$ \\
\hline Bowel ischemia & $1(0.7)$ & $1(1.1)$ & $0(0)$ \\
\hline Limb ischemia & $2(1.5)$ & $2(2.2)$ & $0(0)$ \\
\hline Spinal cord ischemia/neurologic impairment & $0(0)$ & $0(0)$ & $0(0)$ \\
\hline Aortic diameter $\geq 6 \mathrm{~cm}$ & $18(13.2)$ & $17(18.5)$ & $1(2.3)$ \\
\hline Rapid aortic diameter growth $\geq 10 \mathrm{~mm} / \mathrm{y}$ & $10(7.4)$ & $8(8.7)$ & $2(4.6)$ \\
\hline New refractory pain, uncontrollable with medication & $3(2.2)$ & $0(0)$ & $3(6.8)$ \\
\hline Total & $42(30.9)$ & $33(35.9)$ & $9(20.5)$ \\
\hline \multicolumn{4}{|l|}{ Urgent adverse events, $\mathrm{n}(\%)$} \\
\hline Rupture & $3(2.2)$ & $1(1.1)$ & $2(4.5)$ \\
\hline Renal ischemia & $5(3.7)$ & $4(4.3)$ & $1(2.3)$ \\
\hline Bowel ischemia & $1(0.7)$ & $1(1.1)$ & $0(0)$ \\
\hline Limb ischemia & $2(1.5)$ & $2(2.2)$ & $0(0)$ \\
\hline Total & $11(80.1)$ & $8(8.7)$ & $3(6.8)$ \\
\hline \multicolumn{4}{|l|}{ Other events } \\
\hline Resolution of the IMH & $26(59.1)$ & $0(0)$ & $26(59.1)$ \\
\hline Resolution of dissection flap & $2(1.5)$ & $2(2.2)$ & $0(0)$ \\
\hline
\end{tabular}

Values are $\mathrm{n}(\%) . A D$, Aortic dissection; $I M H$, intramural hematoma. 


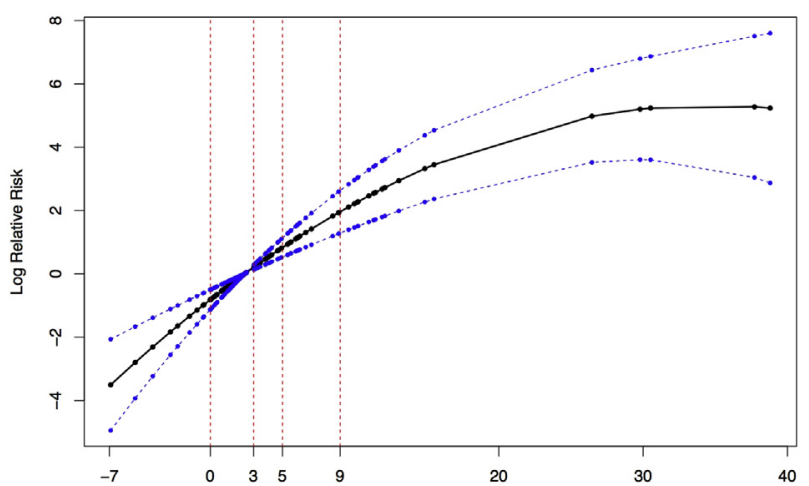

A 6-Month Growth (mm)

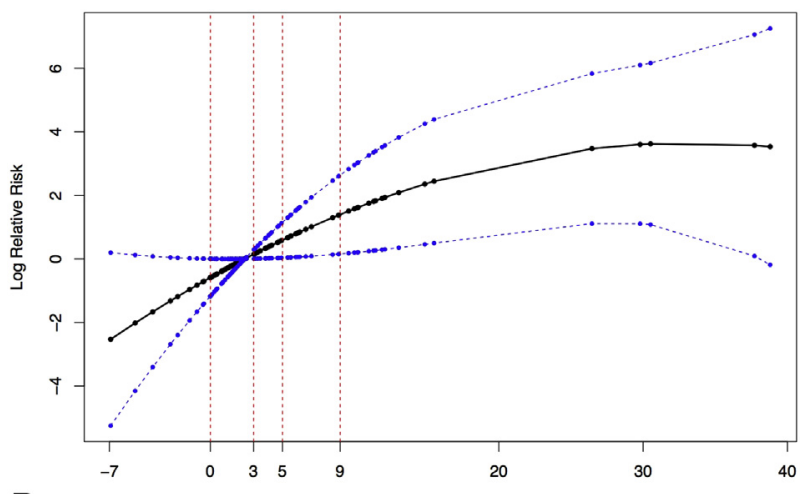

B 6-Month Growth (mm)

FIGURE 2. Relationship between aortic growth rate over the first 6 months and log relative risk for (A) all adverse events including critical size progression and (B) urgent adverse events excluding critical size progression in patients with $\mathrm{AD}$. The median value of growth is $2.4 \mathrm{~mm}$ in the first half year, and this value was chosen as reference value. Blue dotted lines show $95 \%$ confidence intervals. Red dotted vertical lines aid in reading the log relative risk for 4 exemplary slopes of $0,3,5$, and $9 \mathrm{~mm}$ aortic growth in the first half year.

progression. Eight $(9 \%)$ of adverse events were urgent. None of the 6 patients with an isolated abdominal AD developed an adverse event. Resolution occurred in 2 patients with $\mathrm{AD}$, both of which were iatrogenic. During follow-up, 15 patients were treated with open surgical aortic graft replacement, 9 patients were treated endovascularly, and 3 patients were treated with a hybrid approach. In one patient, a single nephrectomy was performed. Five patients died during hospitalizations related to a late adverse event.

With respect to aortic remodeling, 30.4\% (28/92) of patients with type B AD had a growth rate of $5 \mathrm{~mm}$ or greater over the first 6 months; this percentage was greater in patients with connective tissue disease, in whom $50 \%(7 / 14)$ of patients had a $5 \mathrm{~mm}$ or greater 6month aortic growth rate. Figure 2 illustrates the relationship between the 6-month aortic growth and relative risk (RR) of (1) all adverse events and (2) urgent adverse events over a period of 5 years for type B AD. We found that faster aortic growth in the first 6 months, is associated with an increased RR for late adverse events. This effect was significant for all adverse events and for urgent adverse events only $(P<.001$ and $P=.002$, respectively). Compared with a median growth of $2.4 \mathrm{~mm} /$ half year as reference value $(R R=1)$, no growth $(0 \mathrm{~mm} / \mathrm{half}$ year) was associated with a relative risk of adverse events (including size progression) of 0.44 (95\% CI 0.32-0.60). Six-month growths of 3, 5, and $9 \mathrm{~mm}$ were associated with RR of 1.22 (95\% CI, $1.14-$ 1.32), RR of 2.29 (95\% CI, 1.70-3.09), and RR of 7.09 (95\% CI, 3.62-13.91), respectively. The initial aortic diameter was not independently significantly correlated with the occurrence of adverse events $(P=.168)$. For acute adverse events only, no growth was associated with a relative risk of 0.56 (95\% CI, 0.31-1.00). Growth rates of 3,5, and $9 \mathrm{~mm}$ per first half year were associated with RR of 1.16 (95\% CI, 1.01-1.13), RR of 1.81 (95\% CI, 1.04-3.16), and RR of 4.04 (95\% CI, 1.17-13.99), respectively.

\section{Aortic Remodeling and Adverse Events in Patients With IMH}

Of 44 patients with IMH, 9 patients $(21 \%)$ developed an adverse event, with new refractory pain being the most common (3 patients, 33.3\%), followed by aortic rupture ( 2 patients, $22.2 \%$ ), and rapid aortic growth ( 2 patients, $22.2 \%$ ). One patient reached an aortic aneurysm size of $6 \mathrm{~cm}$ during follow-up (without rupture), and one patient developed renal tissue malperfusion related to the IMH. Seven patients with IMH (16\%) developed an intimal tear with dissection flap and false lumen flow during follow-up, and 3 of those patients developed an adverse event. Resolution of the IMH was observed in 26 patients. The probability of resolution at 1 month, 6 months, and 12 months was $9.5 \%$ (95\% CI, 3.7\%$23.4 \%$ ), $39.2 \%$ (95\% CI, 25.2\%-57.4\%), and $58.9 \%$ (95\% CI, 42.7\%-75.8\%), respectively. During followup, 5 patients underwent endovascular aortic repair, and 4 patients were treated with open aortic graft replacement. Two patients died during hospital admission related to a late adverse event. Median aortic growth rate in patients with resorbing IMH was $-0.04 \mathrm{~mm} / \mathrm{month}$ (interquartile range, -0.39 to 0.00 ). In patients with nonresorbing $\mathrm{IMH}$, the median growth was $1.49 \mathrm{~mm} /$ month (interquartile range, 0.11-2.79). The initial dimeter in patients with nonresorbing IMH was significantly larger than in patients with resorbing IMH. In patients without resorption, the mean baseline aortic diameter ( \pm standard deviation) was $42.2 \pm 6.4 \mathrm{~mm}$ versus $36.1 \pm 5.3 \mathrm{~mm}$ in patients with resorption $(P=.0018)$. Resorption occurred in $35 \%(6 / 17)$ of patients with an initial aortic dimeter of $40 \mathrm{~mm}$ or greater, whereas resorption occurred in $74 \%$ 


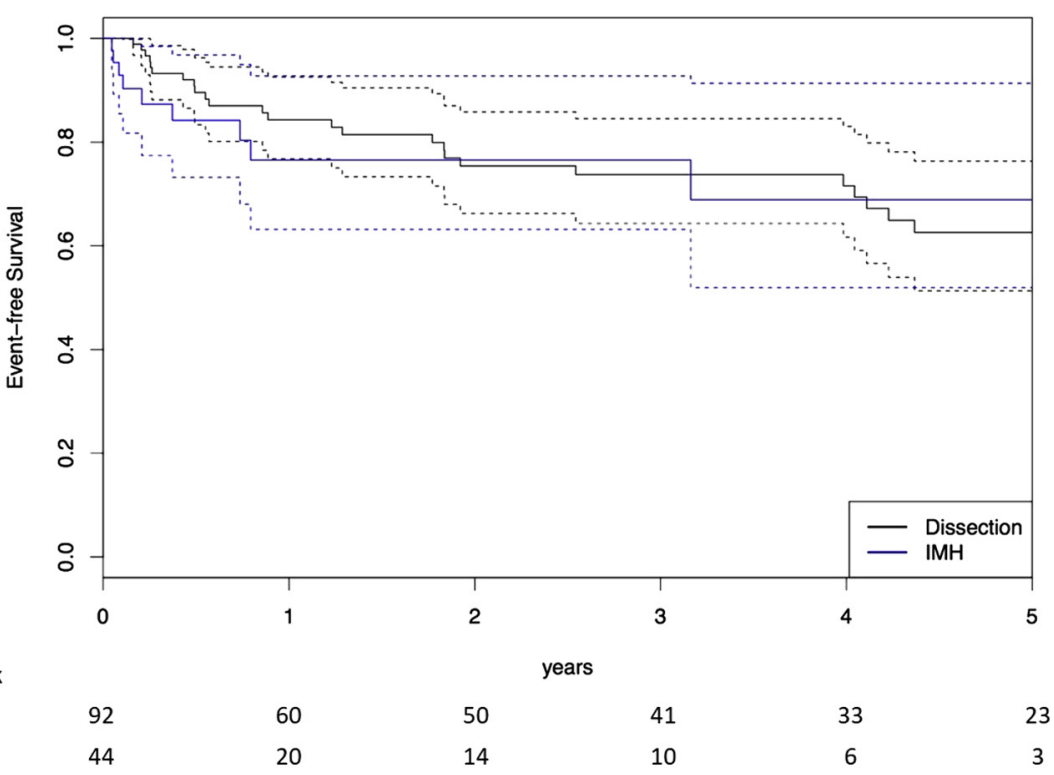

FIGURE 3. Five-year Kaplan-Meier survival curves with confidence intervals (dotted lines) for patients with classic type B AD (Dissection) versus intramural hematoma $(I M H)$. Numbers at risk for each year shown in table below the graph. Log rank: $P=.9629$.

$(20 / 27)$ of patients with initial aortic diameter smaller than $40 \mathrm{~mm}(P=.03)$.

\section{Adverse Event-Free Survival Estimates Between Subgroups of AD and IMH}

Figure 3 shows the Kaplan-Meier survival curves for patients with classic type B AD versus IMH. The cumulative probability of event-free survival for patients with initially uncomplicated type B AD was $84.3 \%(95 \%$
CI, 74.4\%-90.6\%) within the first year, $75.4 \%(95 \%$ CI, $64.0 \%-83.7 \%$ ) within the first 2 years, and $62.6 \%$ $(95 \%$ CI, 68.9\%-73.6\%) within the first 5 years after onset, respectively. The 1-, 2-, and 5-year probability of event-free survival for patients with IMH was $76.5 \%$ (95\% CI, 57.8\%-87.8\%), 76.5\% (95\% CI, 57.8\%$87.8 \%$ ), and $68.9 \%(95 \% \mathrm{CI}, 45.2 \%-83.9 \%)$, respectively. The probability of event-free survival was not different for type $\mathrm{B}$ AD versus IMH (log rank:

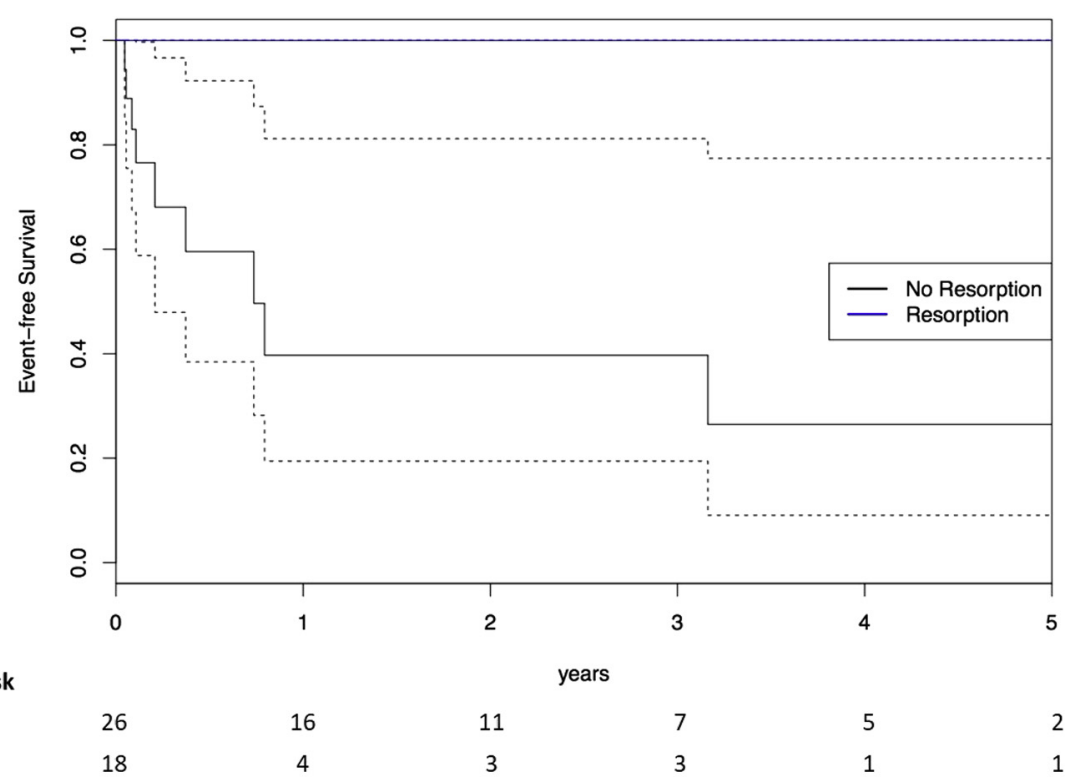

FIGURE 4. Five-year Kaplan-Meier survival curves with confidence intervals (dotted lines) for patients with intramural hematoma with and without resorption. Numbers at risk for each year shown in table below the graph. Log rank: $P<.001$. 


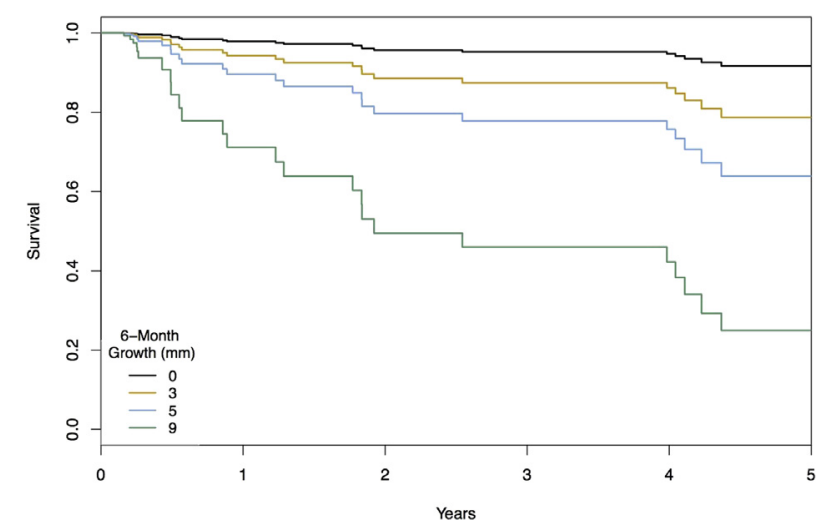

FIGURE 5. Five-year Kaplan-Meier survival curves in patients with uncomplicated type B aortic dissection for 4 aortic growth rates of $0,3,5$, and $9 \mathrm{~mm}$ within the first 6 months from the Cox model.

$P=.963)$. The temporal pattern of events appears different, however, between those groups and even within IMH patients.

Figure 4 shows that all adverse events in patients with IMH occurred in patients without resorption, whereas in patients with resorbing IMH no adverse events were observed (log rank: $P<.001$ ). In patients with IMH without resorption, the majority of adverse events occurred within the first year after onset. In contrast, in patients with type $\mathrm{B} A D$, the cumulative probability of adverse events continues to increase gradually over time. Figure 5 shows the Kaplan-Meier survival estimate from the Cox model for 4 different aortic 6-month growth rates in patients with type $\mathrm{B} A \mathrm{AD}$. Patients with faster aortic growth in the first 6 months showed greater rates of adverse events at 1,2 , and 5 years after onset compared with patients with slower aortic growth. The risk of an adverse event within 2 years after onset was greater than $20 \%$ for patients with growth rates of $5 \mathrm{~mm}$ and greater.

\section{DISCUSSION}

Acute type $\mathrm{B} \mathrm{AD}$ is one of the most challenging aortic diseases. Optimal treatment for patients without complications in the acute phase is the subject of ongoing debates, focusing on the choice between MM and preventive TEVAR. Whether optimal medical treatment with a waitand-see approach represents appropriate care depends on the risk of adverse events during follow-up. Unfortunately, neither the clinical course nor the morphologic evolution of uncomplicated type B ADs and IMH are understood completely. Several analyses have been performed in the past for medically treated type $\mathrm{B} \mathrm{AD}$, but none of them have provided a comprehensive picture of clinical evolution over time based on aortic morphology and aortic growth patterns shortly after the acute event. ${ }^{6,19-26}$ Even less is known about the aortic evolution of acute type B IMH. ${ }^{27}$
Through this retrospective analysis of data gathered in a time when uncomplicated patients were treated conservatively and preventive interventions were relatively uncommon, we attempt to provide insight into the natural history of initially uncomplicated and medically managed acute type B classic ADs and IMH, with a focus on the probability of event-free survival during follow-up in relation to early aortic remodeling.

Baseline patient characteristics in our retrospective cohort are mostly similar for type B AD and IMH. However, there were more patients with Marfan syndrome and other connective tissue diseases in the classic type $\mathrm{B} A D$ group, explaining the significantly younger mean age at onset and lower percentage of patients with hyperlipidemia in this group compared with the IMH group. We found clear differences in the natural history between the type B AD and IMH. More than one half of the patients with IMH (26/44) showed resorption of the hematoma within the first year. However, in patients in whom the hematoma did not resolve, both the initial aortic diameter and aortic growth rates were greater than in the resorbing IMH subgroup as well as in the type B AD group. Most adverse events occur in the first year after onset, and the risk of having an adverse event in that first year is approximately $60 \%$ in patients with nonresorbing IMH. This evaluation might suggest that IMH should be followed closely in the first year, either to diagnose resolution (and allow for a less frequent follow-up imaging regimen) or to detect early signs of adverse events. Once patients have survived the first year without complications, they have a high probability of remaining stable during later follow-up. Specifically, patients with an IMH and an initial diameter $>40 \mathrm{~mm}$ seem to be at increased risk for unfavorable evolution.

For patients with type $\mathrm{B} A D$, the risk of an adverse event in the first year is approximately $15 \%$, but patients remain at risk during later years. An important finding is that the patients with a faster aortic growth rate within the first 6 months represent a group with a significantly greater risk of rupture, malperfusion, or late significant aneurysm formation. This finding strongly suggests that rapid early aortic growth itself seems to be a strong indicator for an unfavorable outcome and-if confirmed-could be considered as an indication for elective intervention.

Definitions of late complications and indications for surgery in chronic dissections based on aortic diameter criteria vary between European and American guidelines, some of which have undergone changes over the past few years. Based on our clinical practice during the study period, a 6-cm maximum aortic diameter of the descending thoracic aorta was considered an adverse event. ${ }^{28}$ This is in accordance with the current European guidelines ${ }^{29}$ on chronic dissections and American guidelines with respect to degenerative descending thoracic aortic aneurysm. ${ }^{30}$ The newest 
American guidelines on chronic dissection recommend elective surgical intervention at an aortic diameter of $55 \mathrm{~mm}$, and other studies discuss intervention at even smaller diameters. ${ }^{31,32}$ If the $55-\mathrm{mm}$ threshold had been applied to our study, 2 more adverse events would have been recorded, with one patient reaching the $55-\mathrm{mm}$ threshold after 5.1 years and another after 8.9 years. Similarly, differences exist for the definition of rapid aortic growth, as the definition of this complication varies in guidelines from $>4 \mathrm{~mm}$ over a year to $>10 \mathrm{~mm}$ over a year. ${ }^{5,29,30}$ We used a $>10-\mathrm{mm}$ increase in aortic diameter over a year as the definition of an adverse event. ${ }^{29}$

Our study is limited by its retrospective design, the variation in the follow-up regimen, and number of CT scans between patients, but most importantly the potential selection bias associated with studies carried out in high-volume referral centers, and by the incomplete follow-up. Approximately one third of patients admitted to our institutions for treatment of uncomplicated type B AD or IMH were followed clinically by outside referring healthcare providers after hospital discharge. Choice of follow-up in other centers typically was based on the location of patient's residence or insurance coverage. We informally compared the baseline characteristics of our study population (Table 1) with those patients followed elsewhere and did not find a significant difference in any of the baseline characteristics, except for the fact that all patients with connective tissue diseases were followed at the 2 participating aortic centers, and none of these patients was followed outside. This is not unexpected and underscores the limits of generalizability of our findings to patients seen in expert aortic centers. Finally, to get a reasonably stable estimate of individual growth rates we used the first 6 months of data for each patient as a covariate, rather using a time-varying Cox model, which can be seen as a limitation of our analysis.

\section{CONCLUSIONS}

More than one third of patients with acute type $\mathrm{B} A \mathrm{D}$ who survive the initial hospitalization without complication and who are medically managed undergo an adverse event within 5 years. In patients with nonresolving IMH, most adverse events are observed in the first year after onset, and in patients with type $\mathrm{B} A D$, a rapid early aortic growth is associated with a high risk of adverse events.

\section{Conflict of Interest Statement}

Authors have nothing to disclose with regard to commercial support.

The authors thank Shannon G. Walters, RT, from the Stanford 3D and Quantitative Imaging Laboratory for his invaluable assistance with quantitative image processing and analysis.

\section{References}

1. Mussa FF, Horton JD, Moridzadeh R, Nicholson J, Trimarchi S, Eagle KA. Acute aortic dissection and intramural hematoma: a systematic review. JAMA. 2016; 316:754-63

2. Olsson C, Thelin S, Stahle E, Ekbom A, Granath F. Thoracic aortic aneurysm and dissection: increasing prevalence and improved outcomes reported in a nationwide population-based study of more than 14,000 cases from 1987 to 2002. Circulation. 2006;114:2611-8.

3. Booher AM, Isselbacher EM, Nienaber CA, Trimarchi S, Evangelista A, Montgomery DG, et al; IRAD Investigators. The IRAD classification system for characterizing survival after aortic dissection. Am J Med. 2013;126: 730.e19-24.

4. Estrera AL, Miller CC, Goodrick J, Porat EE, Achouh PE, Dhareshwar J, et al. Update on outcomes of acute type B aortic dissection. Ann Thorac Surg. 2007 83:S842-5; discussion S846-50.

5. Fattori R, Cao P, De Rango P, Czerny M, Evangelista A, Nienaber C, et al. Interdisciplinary expert consensus document on management of type B aortic dissection. J Am Coll Cardiol. 2013;61:1661-78.

6. Afifi RO, Sandhu HK, Leake SS, Boutrous ML, Kumar V III, Azizzadeh A, et al. Outcomes of patients with acute type B (DeBakey III) aortic dissection: a 13year, single-center experience. Circulation. 2015;132:748-54.

7. Hughes GC, Andersen ND, McCann RL. Management of acute type B aortic dissection. J Thorac Cardiovasc Surg. 2013;145(3 suppl):S202-7.

8. Oikonomou K, Katsargyris A, Ritter W, Spinelli D, Seto Y, Verhoeven EL. Endovascular management of chronic post-dissection aneurysms. Ann Cardiothorac Surg. 2014;3:307-13.

9. Estrera AL, Jan A, Sandhu H, Shalhub S, Medina-Castro M, Nguyen TC, et al. Outcomes of open repair for chronic descending thoracic aortic dissection. Ann Thorac Surg. 2015;99:786-93; discussion 794.

10. Qin YL, Wang F, Li TX, Ding W, Deng G, Xie B, et al. Endovascular repair compared with medical management of patients with uncomplicated type $\mathrm{b}$ acute aortic dissection. J Am Coll Cardiol. 2016;67:2835-42.

11. Durham CA, Cambria RP, Wang LJ, Ergul EA, Aranson NJ, Patel VI, et al. The natural history of medically managed acute type B aortic dissection. J Vasc Surg. 2015;61:1192-8.

12. Nienaber CA, Rousseau H, Eggebrecht H, Kische S, Fattori R, Rehders TC, et al; INSTEAD Trial. Randomized comparison of strategies for type B aortic dissection: the INvestigation of STEnt Grafts in Aortic Dissection (INSTEAD) trial Circulation. 2009;120:2519-28.

13. Nienaber CA, Kische S, Rousseau H, Eggebrecht H, Rehders TC, Kundt G, et al INSTEAD-XL trial. Endovascular repair of type B aortic dissection: long-term results of the randomized investigation of stent grafts in aortic dissection trial. Circ Cardiovasc Interv. 2013;6:407-16.

14. Fattori R, Montgomery D, Lovato L, Kische S, Di Eusanio M, Ince H, et al. Survival after endovascular therapy in patients with type B aortic dissection: a report from the International Registry of Acute Aortic Dissection (IRAD). JACC Cardiovasc Interv. 2013;6:876-82.

15. Walsh SR, Tang TY, Sadat U, Naik J, Gaunt ME, Boyle JR, et al. Endovascula stenting versus open surgery for thoracic aortic disease: systematic review and meta-analysis of perioperative results. J Vasc Surg. 2008;47:1094-8.

16. Cooper DG, Walsh SR, Sadat U, Noorani A, Hayes PD, Boyle JR. Neurological complications after left subclavian artery coverage during thoracic endovascular aortic repair: a systematic review and meta-analysis. J Vasc Surg. 2009;49: 1594-601.

17. Wong CS, Healy D, Canning C, Coffey JC, Boyle JR, Walsh SR. A systematic review of spinal cord injury and cerebrospinal fluid drainage after thoracic aortic endografting. J Vasc Surg. 2012;56:1438-47.

18. Ganaha F, Miller DC, Sugimoto K, Do YS, Minamiguchi H, Saito H, et al Prognosis of aortic intramural hematoma with and without penetrating atherosclerotic ulcer: a clinical and radiological analysis. Circulation. 2002;106: $342-8$.

19. Estrera AL, Miller CC III, Safi HJ, Goodrick JS, Keyhani A, Porat EE, et al. Outcomes of medical management of acute type B aortic dissection. Circulation. 2006;114(1 suppl):I384-9.

20. Jonker FH, Trimarchi S, Rampoldi V, Patel HJ, O'Gara P, Peterson MD et al; International Registry of Acute Aortic Dissection (IRAD) Investigators Aortic expansion after acute type B aortic dissection. Ann Thorac Surg. 2012;94:1223-9.

21. Winnerkvist A, Lockowandt U, Rasmussen E, Rådegran K. A prospective study of medically treated acute type B aortic dissection. Eur J Vasc Endovasc Surg. 2006;32:349-55. 
22. Garbade J, Jenniches M, Borger MA, Barten MJ, Scheinert D, Gutberlet M, et al. Outcome of patients suffering from acute type B aortic dissection: a retrospective single-centre analysis of 135 consecutive patients. Eur J Cardiothorac Surg. 2010;38:285-92.

23. Miyahara S, Mukohara N, Fukuzumi M, Morimoto N, Murakami H, Nakagiri K, et al. Long-term follow-up of acute type B aortic dissection: ulcer-like projections in thrombosed false lumen play a role in late aortic events. J Thorac Cardiovasc Surg. 2011;142:e25-31.

24. Chemelli-Steingruber IE, Chemelli A, Strasak A, Hugl B, Hiemetzberger R, Czermak BV. Evaluation of volumetric measurements in patients with acute type B aortic dissection - thoracic endovascular aortic repair (TEVAR) vs conservative. J Vasc Surg. 2009;49:20-8.

25. Hata M, Sezai A, Niino T, Yoda M, Wakui S, Unosawa S, et al. Prognosis for patients with type B acute aortic dissection: risk analysis of early death and requirement for elective surgery. Circ J. 2007;71:1279-82.

26. Sueyoshi E, Sakamoto I, Hayashi K, Yamaguchi T, Imada T. Growth rate of aortic diameter in patients with type B aortic dissection during the chronic phase. Circulation. 2004;110(11 suppl 1):II256-61.

27. von Kodolitsch Y, Csösz SK, Koschyk DH, Schalwat I, Loose R, Karck M, et al. Intramural hematoma of the aorta: predictors of progression to dissection and rupture. Circulation. 2003;107:1158-63.

28. Chau KH, Elefteriades JA. Natural history of thoracic aortic aneurysms: size matters, plus moving beyond size. Prog Cardiovasc Dis. 2013;56:74-80.

29. Erbel R, Aboyans V, Boileau C, Bossone E, Bartolomeo RD, Eggebrecht H, et al; ESC Committee for Practice Guidelines. 2014 ESC Guidelines on the diagnosis and treatment of aortic diseases: document covering acute and chronic aortic diseases of the thoracic and abdominal aorta of the adult. The Task Force for the
Diagnosis and Treatment of Aortic Diseases of the European Society of Cardiology (ESC). Eur Heart J. 2014;35:2873-926.

30. Hiratzka LF, Bakris GL, Beckman JA, Bersin RM, Carr VF, Casey DE Jr, et al; American College of Cardiology Foundation/American Heart Association Task Force on Practice Guidelines; American Association for Thoracic Surgery; American College of Radiology; American Stroke Association; Society of Cardiovascular Anesthesiologists; Society for Cardiovascular Angiography and Interventions; Society of Interventional Radiology; Society of Thoracic Surgeons; Society for Vascular Medicine. 2010 ACCF/AHA/AATS/ACR/ASA/ SCA/SCAI/SIR/STS/SVM guidelines for the diagnosis and management of patients with Thoracic Aortic Disease: a report of the American College of Cardiology Foundation/American Heart Association Task Force on Practice Guidelines, American Association for Thoracic Surgery, American College of Radiology, American Stroke Association, Society of Cardiovascular Anesthesiologists, Society for Cardiovascular Angiography and Interventions, Society of Interventional Radiology, Society of Thoracic Surgeons, and Society for Vascular Medicine. Circulation. 2010;121:e266-369.

31. Kim JB, Kim K, Lindsay ME, MacGillivray T, Isselbacher EM, Cambria RP, et al. Risk of rupture or dissection in descending thoracic aortic aneurysm. Circulation. 2015;132:1620-9.

32. Kinlay S. Does this study make my aorta look fat? Circulation. 2015;132:1600-1.

Key Words: aortic dissection, aortic dissection complication, aneurysm aorta, imaging aorta, computed tomography, aortic intramural hematoma 